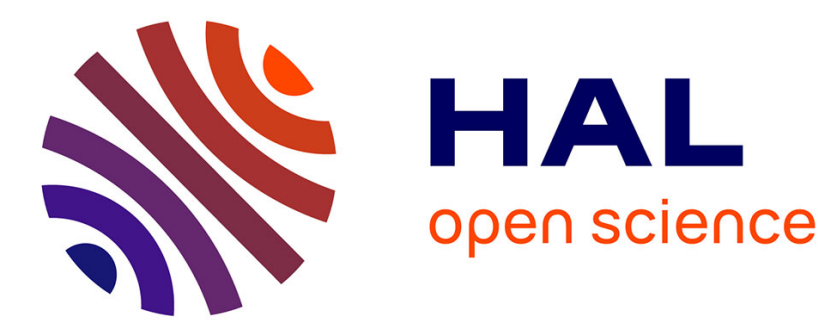

\title{
Third-party logistics providers offering form postponement services: value propositions and organisational approaches
}

Alessio Trentin

\section{- To cite this version:}

Alessio Trentin. Third-party logistics providers offering form postponement services: value propositions and organisational approaches. International Journal of Production Research, 2010, pp.1. 10.1080/00207541003623414 . hal-00581540

\author{
HAL Id: hal-00581540 \\ https://hal.science/hal-00581540
}

Submitted on 31 Mar 2011

HAL is a multi-disciplinary open access archive for the deposit and dissemination of scientific research documents, whether they are published or not. The documents may come from teaching and research institutions in France or abroad, or from public or private research centers.
L'archive ouverte pluridisciplinaire HAL, est destinée au dépôt et à la diffusion de documents scientifiques de niveau recherche, publiés ou non, émanant des établissements d'enseignement et de recherche français ou étrangers, des laboratoires publics ou privés. 


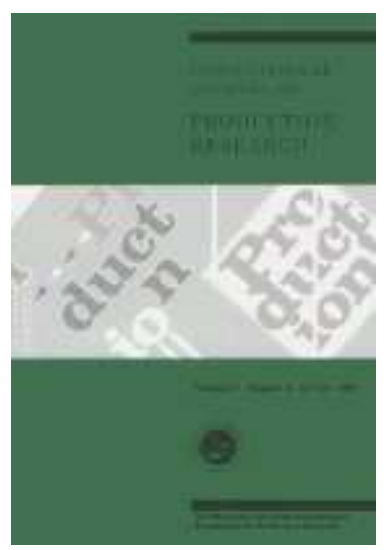

Third-party logistics providers offering form postponement services: value propositions and organisational approaches

\begin{tabular}{|r|l|}
\hline Journal: & International Journal of Production Research \\
\hline Manuscript ID: & TPRS-2009-IJPR-0327.R2 \\
\hline Manuscript Type: & Original Manuscript \\
\hline $\begin{array}{r}\text { Date Submitted by the } \\
\text { Author: }\end{array}$ & 04-Nov-2009 \\
\hline Complete List of Authors: & $\begin{array}{l}\text { Trentin, Alessio; Università di Padova, Dipartimento di Tecnica e } \\
\text { Gestione dei sistemi industriali; Zaragoza Logistics Center }\end{array}$ \\
\hline Keywords: & POSTPONEMENT, MASS CUSTOMIZATION \\
\hline Keywords (user): & third-party logistics, case study-based research \\
\hline &
\end{tabular}

\section{s) ScholarONE" \\ Manuscript Central}


Third-party logistics providers offering form postponement services: value propositions and organisational approaches

\author{
Alessio Trentin* \\ Dipartimento di Tecnica e Gestione dei sistemi industriali, Università di Padova, Stradella S. Nicola 3, \\ 36100 Vicenza, Italy \\ Zaragoza Logistics Center, Avenida Gómez Laguna 25, 50009 Zaragoza, Spain
}

${ }^{*}$ Email: alessio.trentin@ unipd.it

http://mc.manuscriptcentral.com/tprs Email: ijpr@lboro.ac.uk 


\section{Third-party logistics providers offering form postponement services: value propositions and organisational approaches}

In today's global supply chains, third-party logistics providers (3PLs) can play an important role in implementing the principle of form postponement (FP). This proposes that activities creating product variety and the associated production mix decisions are deferred along a product family manufacturing and distribution process as long as possible. While both FP and third-party logistics have increasingly drawn the attention of the academic community over the last few years, less research has been done on FP supported by 3PLs. The present paper empirically investigates how 3PLs can deliver value to companies offering product variety by providing FP services, defined as the carrying out of variety-creating activities on behalf of these companies close to the target markets. Our findings indicate that through an FP service, a 3PL can give its customers two different kinds of benefits: either improved performance in serving the customer's existing markets or entry into new geographical markets. Further, our results show that through the choice of the organisational solution for FP service provision, the 3PL can increase FP value by mitigating a number of disadvantages that the customer might incur in case of in-house implementation of FP. Challenges that the 3PL needs to overcome to actually provide these potential benefits are also identified. The paper concludes by discussing the implications of our findings for both practice and research on FP.

Keywords: form postponement; delayed product differentiation; third-party logistics; mass customisation; case study-based research.

\section{Introduction}

Form postponement is an operations design principle that more and more companies today are turning to (Matthews and Syed 2004) under the effect of increasing product variety and customisation (Pine 1993, Bayus and Putsis 1999, Funke and Ruhwedel 2001). The principle of form postponement (FP) proposes that companies defer their commitment of resources to a specific end-product in the manufacturing and distribution process as long as possible (Alderson, 1950; Heskett, 1977). Application of FP requires deferring at least one product differentiation activity (PDA), which specialises the work-in-progress into particular end-products, and the decision driving such activity (Lee, 1996; Garg and Tang, 1997). By deferring a PDA, FP allows for the collecting of new information about customer demands (e.g., actual customer orders, or updated sales forecasts in case of make-to-stock production) prior to the making of the decision driving the PDA, thereby reducing uncertainty (Yang et al. 2004a, Forza et al. 2008, Wong et al. 2009).

Third-party logistics providers (3PLs) can play an important role in FP implementation (van Hoek 2000a, Yang et al. 2007), owing to the increasing geographical dispersion of supply chains. As production moves farther away from primary markets, there is a greater incentive to implementing FP by placing PDAs in the distribution channel. By doing so, companies serving 
global markets avoid making decisions on final product configurations far ahead of the moment of customer purchase and assure high responsiveness, while retaining scale economies at centralised factories (Cooper 1993, Van Hoek 1998). With more and more companies trying to place PDAs in the distribution channel, it comes as no surprise that 3PLs, especially large 3PLs operating on a continental or even global scale, see the carrying out of PDAs on behalf of manufacturing companies as a viable extension of their service offerings (van Hoek 2000a). By doing so, 3PLs can raise turnover in a higher-margin area of the supply chain than the increasingly commodified traditional logistics services (van Hoek 2000b). Moreover, by supplementing transport- and warehousing-based services with the carrying out of PDAs in the distribution channel, 3PLs can reap the benefits of deeper relations with existing customers and increased customer loyalty (van Hoek 2000a).

While both the literature on FP (van Hoek 2001, Yang et al. 2004b) and the literature on third-party logistics (Selviaridis and Spring 2007, Marasco 2008) have rapidly grown over the last few years, less attention has been paid so far to FP supported by 3PLs. The present paper aims to augment our understanding of how 3PLs can deliver value to companies offering product variety by providing FP services, defined as the carrying out of PDAs on behalf of these companies close to the target markets. Accordingly, the paper empirically investigates the following two research questions: What FP services can a 3PL offer and how do they create value for the customer buying the service? Moreover, what organisational solutions can a 3PL adopt to provide an FP service, how do they influence value to the 3PL's customer, and what are the associated challenges for the 3PL?

The remainder of this paper is organised as follows. Section 2 provides motivations for our research in the context of the existing literature on FP. Section 3 describes and justifies the inductive research design we used to address our research questions. Three observations linking 3PL-provided FP services, value to the 3PL's customer, organisational approaches, and enabling or hindrance factors are presented, along with the evidence supporting each observation, in Section 4. Section 5 concludes by discussing the contribution of this study to the FP literature, the managerial implications of our findings, as well as their limitations and associated opportunities for future research.

\section{Background}

The notion of FP first appeared in literature in the 1950s, when Alderson $(1950,1957)$ proposed postponement in product differentiation as a principle to improve the efficiency of a production and distribution system. Product differentiation may occur in product form and identity, thereby resulting in different varieties, or in product location, thus leading to geographical dispersion of inventories. Postponement of changes in product form and identity has been subsequently termed in literature as FP, delayed product differentiation, late customisation, manufacturing postponement, or simply postponement (Swaminathan and Lee 2003, Forza et al. 2008). On the other hand, postponement of changes in inventory location has been later called logistics postponement, delayed geographic differentiation, place postponement, or time postponement (Pagh and Cooper 1998, Aviv and Federgruen 2001).

The majority of extant literature addresses FP on a single company level (Yeung et al. 2007). From such a perspective, many studies have researched FP antecedents, focusing on market characteristics, product characteristics, and production process characteristics that influence FP (Yang et al. 2004b). Market characteristics promoting FP include factors such as a high number of product variants (Zinn 1990, Johnson and Anderson 2000), high uncertainty and 
substitutability of product variant demands (Zinn and Bowersox 1988, Aviv and Federgruen 2001), and short product life cycles (van Hoek et al. 1998, Chiou et al. 2002). In turn, product characteristics favouring FP encompass high product value (Zinn and Bowersox 1988, Chiou et al. 2002), high product modularity (Lee and Tang 1997, Yang et al. 2004a), and high component standardisation (Lee 1996, Harrison and Skipworth 2008). Finally, production process characteristics facilitating FP comprise low capital intensity and no need for special capabilities at the postponed PDA (van Hoek 1997, Pagh and Cooper 1998), high process modularity (Feitzinger and Lee 1997, Swaminathan and Lee 2003), and availability of substantial excess capacity at the deferred activity (Gupta and Benjaafar 2004, Harrison and Skipworth 2008).

Similarly, from a single company's perspective many studies have researched FP consequences, focusing on FP operational outcomes rather than on its strategic implications (Anand and Girotra 2007). For a detailed discussion of previous research findings on FP effects on six performance dimensions (i.e., inventory-holding costs, delivery lead-times, processing costs, transport costs, order specification flexibility, and quality conformance), we refer to Forza et al. (2008). They distinguish three mutually exclusive and exhaustive types of FP at the company level of analysis: From-forecast-to-order-driven FP, Remaining-forecast-driven FP and Remaining-order-driven FP. Further, they show that the effects of FP on a given performance dimension and/or the mechanisms explaining such effects often vary according to the type of FP that is being considered. Notably, a few of these effects and mechanisms, such as lower transport costs due to the changed nature of the items shipped to distribution centres or higher processing costs owing to fixed asset duplication at distribution centres, are specific to the situation in which a PDA is moved into the distribution channel (Zinn and Bowersox 1988, Lee and Billington 1994).

Less research has been devoted to examining FP from an inter-organisational perspective (van Hoek 2001, Yeung et al. 2007). A few studies address this topic at the whole supply chain level of analysis. Yang and Burns (2003) argue that postponement in general, including FP, requires that uncertainties in the supply chain be reduced as much as possible through internal and external integration. Such an argument is supported by a subsequent exploratory survey conducted by Yang et al. (2005a), who find that most of the highest ranked barriers to postponement were related to how a company manages its external networks (both suppliers and customers). Yang et al. (2007) further highlight the importance of choosing appropriate interorganisational structures to successfully implement postponement. In turn, Yeung et al. (2007) investigate how one company's postponement decision is affected by the company's degree of external integration and by the market structure in both the upstream and downstream parts of the company's supply chain. Finally, building on Bucklin's (1965) seminal work on the combined principle of postponement and speculation, García-Dastugue and Lambert (2007) show that when one organisation implements postponement without considering its impact on the other supply chain members, inventory-holding costs for the supply chain as a whole may turn out to be higher.

Other studies researching FP from an inter-organisational perspective focus on either the upstream or the downstream part of a company's supply chain. Examining the upstream part, Prasad et al. (2005) find that close integration with suppliers is essential to prevent FP from impairing product delivery lead-times. In turn, Kumar and Wilson (2009) show that when manufacturing operations are moved to overseas suppliers, FP can help minimise the inventory cost impact of increased lead-times. Looking at next-tier customers, however, Krajewsky et al. (2005) link higher levels of FP application to tighter contract restrictions on the magnitude and 
frequency of the changes that customers are allowed to make to order quantities. In turn, Brown et al. (2000) and Davila and Wouters (2007) investigate the operational benefits of implementing FP by transferring PDAs to customers. Finally, two survey-based studies focus on the role of 3PLs in implementing FP by moving PDAs into the distribution channel. Van Hoek and van Dierdonck (2000) and van Hoek (2000a) find that 3PLs were mostly involved in relatively simple PDAs, such as packaging and labelling, and that 3PL involvement in FP implementation was expected to grow in the years to come. Moreover, van Hoek's (2000a) results indicate that a higher rate of engagement of 3PLs in FP implementation was associated with the use of integration mechanisms such as account management and comprehensive performance measurement systems covering production and customisation activities.

In summary, our review of the FP literature indicates that while the carrying out of postponed PDAs in the distribution channel has been widely discussed (e.g., Lee et al. 1993, Twede et al. 2000, Shao and Ji 2008), less attention has been paid to examining such an FP strategy when it involves other supply chain members than the manufacturing company. In particular, while the possibility of outsourcing PDAs placed in the distribution channel to 3PLs has been well documented in the FP literature (e.g., van Hoek 2000a, Yang and Burns 2003, Yang et al. 2007), research on the contribution that a 3PL can make to a company's FP strategy is still in its infancy.

\section{Research objectives and method}

This study aims to contribute to a better understanding of how 3PLs can deliver value to companies offering product variety by providing FP services, defined as the carrying out of PDAs on behalf these companies close to the target markets. More specifically, our study addresses the following research questions:

RQ1. What FP services can a 3PL offer and how do they create value for the customer buying the service?

RQ2. What organisational solutions can a 3PL adopt to provide an FP service, how do they influence value to the 3PL's customer, and what are the associated challenges for the 3PL?

Owing to the lack of research examining these questions, our inquiry employed a case study approach (Yin 1984, Eisenhardt 1989). When little is known, the richness and detail of qualitative data are crucial in identifying key constructs relevant to explaining the focal phenomenon (Patton, 1990). In addition, qualitative data are particularly useful for examining "how" and "why" questions (Yin 1984), and understanding how and why FP services create value for the 3PL's customer and how and why FP service organisational solutions influence such value was one of the fundamental aims of our research.

The unit of analysis, in this exploratory study, was a product-customer combination-namely a given product type of a given customer-for which a 3PL carries out at least one PDA on behalf of the customer. This is an appropriate unit of analysis, as FP applies to a product that is made in at least two different variants sharing the same basic functionalities and common manufacturing activities (Garg and Tang 1997, Gupta and Krishnan 1998). Accordingly, those product-customer combinations for which the 3PL performs transformational activities that do not create product variety (e.g., ironing cloths shipped in bulk from overseas factories) were excluded from the reference population. 
Cases were chosen from among the product-customer combinations served by one of the world's leading logistics groups, which provides both traditional logistics services and valueadded services (VASs) through an international network linking more than 200 countries and territories worldwide. This 3PL presented an interesting context for our research for two reasons. First, the 3PL was supplying a broad range of FP services to several product-customer combinations under a variety of labels, such as postponement, contract assembly, kitting, copacking, etc. ${ }^{1}$ Secondly, the 3PL was interested in better understanding both the mechanisms through which FP services can create customer value and the challenges in improving such services. To increase the likelihood of observing different types of FP service and different types of FP service organisational solution, we selected cases from different industries or, if an industry is the same, from different types of product (Table 1).

Insert Table 1

Data were collected in two rounds partially overlapping with data analysis to take advantage of flexible data collection (Eisenhardt 1989). During the first round, we gathered information according to a semi-structured research protocol covering the following areas: customer profile, product family profile, supply chain configuration, facility profile, postponed PDA characteristics, FP service outcomes, FP service enablers, and FP service obstacles. To probe particular themes emerging from first-round data analysis, in the second round of data collection we added one case (i.e., case 6) and adjusted the research protocol to gather additional information on the role of resource-sharing in the provision of FP services. In particular, we defined a comprehensive list of resources that a 3PL may use in serving a product-customer combination, which list covers the following resource categories: facility, equipment, workforce, information technology (IT) system, transport, administrative staff, licences and other services. Based on this list, for each case we gathered information on whether and which resources were systematically shared with other product-customer combinations, as well as information on the characteristics of the product-customer combinations among which resources were shared.

Data were collected from three main sources: open-ended interviews, archival documents, and direct observations. Each case involved at least one visit to the 3PL site where the productcustomer combination was served. Furthermore, we conducted in-depth interviews with middleand upper-level managers in charge of the whole site or the specific FP service within the site. To reduce observer bias (Voss et al. 2002) and simultaneously enhance the creative potential of the study (Eisenhardt 1989), 70\% of the in-depth interviews were conducted by two investigators. Additional primary data were collected through shorter interviews with 3PL executives in charge of business development in the industries from which the cases had been selected. Finally, primary information obtained from manager interviews and site visits were supplemented with secondary data from archival documents collected before and after the visit, such as responses to requests for quotation and internal presentations.

1. The exact number of product-customer combinations that the 3PL provides FP services is not available. This is because, within the 3PL organization, FP services often go under the same labels as other contract manufacturing services that do not involve execution of PDAs. During our preliminary check of the 3PL's FP services in Europe, the 3PL informed us about 32 cases that, in the company's opinion, were relevant to our research. After careful examination, however, we ascertained that only 18 out of these 32 cases were undoubtedly cases of FP. 
Data analysis consisted of two steps, namely within-case analysis and cross-case analysis. Following Eisenhardt's (1989) suggestions, within-case analysis involved writing detailed descriptions of the selected cases in order to become intimately familiar with each case as a stand-alone entity. Additionally, open and axial coding techniques (Strauss, 1987) were used to reduce qualitative data and identify the main themes and variables relevant to the research questions. In the subsequent phase of cross-case analysis, we compared and classified the selected cases according to the related supply chain configurations before and after FP service implementation and according to the resource-sharing profile observed in each case. Moreover, variable-oriented comparisons were made through comparative matrices to highlight patterns. The insights generated from cross-case analysis were finally submitted to the criticism of informants and other 3PL executives in order to check the correctness of our interpretation and discuss generalisability of our findings.

\section{Results}

\subsection{Form postponement services and their value propositions}

The data from this research indicate that a 3PL may provide different types of FP service, which have the potential to create value for the 3PL's customer through different mechanisms. The empirical evidence on the FP services supplied in the selected cases and on the value delivered to the 3PL customer is summarised in Table 2. Moreover, pictorial representations of the offered FP services are provided in Figures 1-4.

\section{Insert Table 2}

A first type of FP service comprises those situations in which the service provider takes on responsibility for creating product variants that the 3PL's customer used to produce upstream in the supply chain. Stated otherwise, this type of FP service applies to existing PDAs, which create product variants for geographical markets that the 3PL's customers were already serving. Accordingly, we refer to this type of FP service as an existing-PDA FP service. The 3PL's customers may take advantage of this type of FP service to improve their operational and financial performance in supplying their existing geographical markets, as shown by cases 1-4.

In case 2, an originally forecast-driven PDA ends up being carried out on a to-order basis (Figure 1). Accordingly, this existing-PDA FP service may be classified in Forza et al. "s (2008) terms as a from-forecast-to-order-driven-PDA FP service. A fundamental benefit, in this case, is that the FP service enables order-driven execution of PDAs without excessive increase of delivery lead-time. The manufacturer no longer incurs the risks and associated costs of inaccurately forecasting the demand mix relative to the varieties created by the postponed PDA. Furthermore, the increase of delivery lead-time due to elimination of finished goods speculative stock is alleviated as compared to the situation in which the PDA were performed on a to-order basis at a site farther away from the target markets. Case 2 also indicates financial benefits of this FP service, as the manufacturer need not invest in setting up a facility to create varieties based on customer orders close to the target markets. Finally, there are other financial and operational advantages, such as reduced overhead and increased volume flexibility, that are contingent on the specific organisational approach adopted by the 3PL to provide the service and are, therefore, discussed in Section 4.2.

Insert Figure 1 
In cases 1 and 4, an originally forecast-driven PDA continues to be carried out on a toforecast basis after FP service implementation (Figure 2). Accordingly, this existing-PDA FP service may be classified in Forza et al. 's (2008) terms as a remaining-forecast-driven-PDA FP service. A fundamental benefit, in this case, is that the FP service enables the manufacturer to reduce finished goods inventory-holding and shortage costs without sacrificing on-hand availability of end-products. The postponed PDA is performed close to the target markets and, hence, the forecast window associated with this activity is shorter and the related forecast is more accurate. Furthermore, lead-times in responding to unanticipated market requirements are shorter. Common to both case 1 and case 4 is also the financial benefit of reduced investment in fixed assets, as compared to the situation in which the manufacturer itself sets up a facility to carry out the PDA close to the target markets. Finally, other financial and operational advantages of this FP service, such as the reduced transport costs and lower overhead observed in either case 1 or case 4 , depend on the specific PDA to which the service is applied or the specific organisational approach adopted by the 3PL to supply the service.

\section{Insert Figure 2}

In case 3, finally, an originally order-driven PDA continues to be executed on a to-order basis after FP service implementation (Figure 3). Accordingly, this existing-PDA FP service may be classified in Forza et al. 's (2008) terms as a remaining-order-driven-PDA FP service. A fundamental benefit, in this case, is that the FP service enables the manufacturer to improve customer service through greater order specification flexibility. The manufacturer's customers have more time to make their decisions on the product feature(s) added by the postponed PDA without time and cost performance being worsened, as the PDA is carried out later in the order fulfilment process. Case 3 also indicates financial benefits of this FP service, as the manufacturer need not invest in setting up a facility to perform the PDA close to the target markets. Finally, there are other financial and operational advantages, such as reduced overhead and distribution costs, that are contingent on the specific organisational approach adopted by the 3PL to provide this FP service.

Insert Figure 3

When we analyse the FP services supplied in cases 5-7, however, a different value-creating mechanism emerges. In all these cases, the fundamental benefit of the provided service is to enable the 3PL's customer to enter and profitably serve new geographical markets. Supplying such new markets requires creating new product variants, but the 3PL's customer could not profitably make these varieties in-house. It might be too costly for the 3PL's customer to ensure service levels in line with incumbents by creating these varieties at its factory, while the investment needed to set up a facility to perform the PDA close to the target markets might be excessively high (see case 7). Alternatively, the 3PL's customer might be a service company or a fabless company that would not find it advantageous to set up a facility and develop manufacturing competences to carry out the PDA in-house (see cases 5 and 6). In any case, the 3PL's network of facilities enables the 3PL's customer to create the product variants needed to address the new target markets in a profitable manner. Not only is the initial investment minimised, but also operational performance is improved by virtue of the product variants being created close to the target markets. Additionally, further benefits, such as the reduced overhead and operating costs observed in cases 6 and 7, arise from the specific organisational approach adopted by the 3PL to provide the service.

In cases 5-7, in short, the FP service applies to a PDA that the 3PL's customer could not profitably carry out, and results in the 3PL performing the PDA in the distribution channel, close 
to the new target markets (Figure 4). Accordingly, we refer to this type of FP service as a PDAenabling FP service. Involving a new PDA, rather than an existing one, this type of FP service cannot be mapped onto the FP types defined by Forza et al. (2008).

\section{Insert Figure 4}

Based on the cross-case analysis, the following observation concerning FP services and their value propositions can be made:

Observation 1. FP services have the potential to create value for the $3 P L$ 's customer either by improving operational and financial performance in serving existing geographical markets (existing-PDA FP services) or by enabling entry into new geographical markets (PDA-enabling FP services).

While our empirical inquiry has focused on the mechanisms through which FP services can create value for the company buying the service, it is important to acknowledge the possible drawbacks of using FP services from the 3PL's customer perspective. When a PDA is moved into the distribution channel, processing costs may increase because labour and equipment required by the postponed activity need to be duplicated at multiple distribution sites. Additional costs are also incurred to pack and unpack the semi-finished products shipped from the manufacturing plant to the distribution sites where finished product variants are created. Furthermore, if the postponed PDA is carried out in the distribution channel on a to-order basis, processing costs may rise due to the loss of manufacturing scale economies at the postponed activity or because of the need for keeping excess capacity at distribution sites to enable quick response to demand peaks. Use of an FP service may also lead to higher quality assurance costs, if the level of training and experience of the people responsible for PDA execution in the distribution channel is lower than at the manufacturing plant. Other possible disadvantages of FP services include higher finished goods distribution costs and longer delivery lead-times. When the postponed PDA is carried out in the distribution channel on a to-order basis, logistics scale economies are lost, owing to direct deliveries to customers, and the work content of the order fulfilment process increases, as end-products are no longer available on-hand. Interestingly, some of the abovementioned drawbacks of using FP services can be mitigated if 3PLs succeed in supplying such services through appropriate organisational solutions, as we will discussed hereinafter.

\subsection{Form postponement service organisational approaches, effects on customer value and implementation challenges}

The data from this research indicate that different organisational approaches may be used to provide an FP service to a given product-customer combination, with different effects on the value delivered to the 3PL's customer. The empirical evidence on the organisational solutions adopted in the selected cases, their impact on customer value and the associated challenges for the 3PL is summarised in Table 3. Pictorial representations of the adopted organisational solutions are also provided in Figure 5.

$$
\text { Insert Table } 3
$$

Insert Figure 5

One fundamental approach to supplying an FP service to a given product-customer combination is to use resources dedicated to that combination: namely, an ad-hoc facility. This 
ad-hoc approach is illustrated by cases 1, 4 and 5, in which all, or almost all, the resources employed to provide the service are dedicated to a single product-customer combination.

The alternative approach to supplying an FP service consists of using a platform, defined as a collection of resources systematically shared by a set of product-customer combinations. This platform approach is common to cases 2, 3,6 and 7. When we compare these cases, however, different solutions emerge under the same "platform" label. In cases 2 and 3, resources are shared within a single facility among different product families of the same customer and, therefore, we refer to such a solution as a multi-product platform. Resource-sharing occurs within a single facility in case 6 as well, but involves different customers with similar products. Accordingly, such a solution will hereafter be labelled as a multi-customer platform. In case 7, finally, resources are also shared between distinct facilities located in close proximity to each other and, hence, we refer to such a solution as a campus-style platform.

The data collected in this study also indicate that in the supplying of an FP service, the platform approach has the potential to create more value for the 3PL's customer than the ad-hoc approach. All the cases in which the ad-hoc approach is adopted exhibit problems of capacity underutilisation, especially where demand fluctuations are wider because of strong seasonal peaks (cases 4 and 5). Conversely, capacity utilisation increases in all cases in which the platform approach is used, even where promotions lead to high demand variability (case 6). This is because fixed assets are systematically shared among multiple product-customer combinations. Consequently, fewer resources are needed to serve each of these combinations and, hence, unit processing costs are lower.

Besides increasing fixed asset productivity, the platform approach tends to reduce dependence on temporary labour without sacrificing volume flexibility. All the cases in which an ad-hoc facility is used exhibit heavy reliance on temporary labour as a means of coping with demand peaks that are often strong and unpredictable. In case 5, for example, sometimes the 3PL has to quadruple production volume from one week to the next because of a promotion. However, the 3PL does not receive any prior information from its customer, who is concerned about possible dissemination of confidential promotion-related information among competitors. Heavy dependence on temporary labour may limit responsiveness, as this type of workforce may be difficult to find in the local market, especially at certain times of year such as just before Christmas (case 5). Additionally, strong dependence on temporary labour may lead to higher costs because of production losses owing to worker inexperience (case 5) and because of the need for multiple checks in the production lines to assure quality (case 1). On the contrary, the cases in which the platform approach is adopted show a lower dependence on temporary labour even though the postponed PDA is always labour-intensive and demand variability is sometimes high. In case 6 , for example, requirements for additional workforce at a given product-customer combination are usually met through sharing of permanent staff with the other product-customer combinations served by the platform. In this case, the 3PL hires temporary workers only in July, when demand peaks for the product-customer combinations served by the platform overlap. Notably, not only is volume flexibility preserved, but may even improve, especially when longer training is needed to perform the PDA (case 6) and temporary workers are more difficult to find in the local market (case 2). This is because momentary excess capacity at one productcustomer combination can be quickly diverted to another product-customer combination where capacity is insufficient, without the need for additional training.

Finally, using the platform approach in the provision of an FP service may increase customer value by reducing costs in the distribution of the product variants created by the postponed PDA.

http://mc.manuscriptcentral.com/tprs Email: ijpr@lboro.ac.uk 
In cases 2, 3 and 7, distribution costs are lower because the product-customer combinations served by each of these platforms have partially overlapping delivery points and are distributed by the same 3PL. As product-customer combinations with overlapping delivery points are served within the same facility or group of facilities located close to each other, loading points overlap as well. Consequently, shipments of finished goods may be consolidated, if the company in charge of distribution is the same.

Integrating the above arguments concerning platform approach advantages in terms of fixed asset utilisation, dependence on temporary labour, volume flexibility, and distribution costs, we make the following observation:

Observation 2. In the supplying of an FP service, the platform approach has the potential to create more value for the 3PL's customer than the ad-hoc approach.

This observation focuses on the potential benefits of the platform approach. Many factors, however, influence both the possibility and the cost of systematically sharing resources among a given set of product-customer combinations without impairing responsiveness. The data from this research indicate a number of factors that enable or hinder resource-sharing among productcustomer combinations served within the same facility or the same group of facilities located close to each other. Implementing such enabling factors and minimising such hindrance factors represent just as many challenges that a 3PL will face in applying the platform approach. As witnessed by case 1 , in which only a few resources such as general site management, licences, security service and other auxiliary services are shared, bringing different product-customer combinations together is not sufficient to create a platform and enjoy its potential benefits.

One factor hindering platform approach implementation is heterogeneity of workforce training requirements, which increases the cost of sharing direct labour. In cases 1, 2 and 3, in which significantly different product types are processed within the same facility, cross-training of workers is too costly. Consequently, either VAS operators are not shared at all (case 1), or sharing only occurs when complex PDA operators are employed to carry out simpler PDAs (cases 2 and 3). Conversely, in case 7, workers are systematically shared among most productcustomer combinations. A few combinations, however, require such different training from the rest, owing to their product complexity or regulations, that they need a dedicated workforce. In case 6, finally, the workforce is shared among all product-customer combinations, but due to partially different processes and procedures, training requirements are not exactly the same for all combinations and, therefore, some cross-training is needed. Case 6 shows that even when customers with similar products are brought together, sharing of workforce may not be free.

A second hindrance factor in platform approach implementation is heterogeneity of equipment requirements, which increases the cost of sharing equipment and, at times, of indirect labour such as maintenance technicians. Cases 1,2,3 and 7 all exhibit some product-specific equipment, such as an antistatic floor for PoS terminals in case 3 or controlled-temperature storage containers for clinical trials in case 7, which would be too costly to use for the other products served within the same facility or campus. Furthermore, because of equipment specificity, clinical trials in case 7 require dedicated maintenance operators. Conversely, in case 6 , in which the facility serves customers with similar products, the clean room where medication labelling and display building take place are shared without limitations.

Another factor that hinders resource-sharing among product-customer combinations is similarity of their target markets, meaning that the product-customer combinations are in direct 
competition and/or have overlapping demand patterns. When different product-customer combinations are in direct competition, it may be impossible not only to share workforce or equipment, but even to serve these combinations under the same roof, owing to confidentiality issues (cases 4 and 5). Furthermore, demand patterns for these combinations tend to overlap. When product-customer combinations face demand peaks and valleys simultaneously, opportunities for resource-sharing are slim, regardless of confidentiality issues, because capacity must be held at peak demand for each combination in order to ensure high responsiveness. Unsurprisingly, in cases 6 and 7, which exhibit high levels of resource-sharing, at least main customers are not direct competitors and demand patterns are, for the most part, complementary. This makes it possible for the 3PL to systematically share resources and, therefore, reduce the total capacity required without impairing the ability to match supply with demand and, hence, without delivery delays. Notably, there is less chance that direct competition and overlapping of demand patterns are a problem when different product types of the same customer are brought together, as witnessed by cases 2 and 3 .

A fourth factor that negatively affects resource-sharing is heterogeneity of IT systems. Using different IT systems for different product-customer combinations not only prevents sharing of IT resources (case 1), but also may lead to duplication of IT staff. In case 6, for example, there are two people responsible for IT management, each trained in working with one of the two main systems in use at the facility. Different IT systems also make it more difficult to share processes and procedures, thereby hindering sharing of workforce (cases 6 and 7). The problem of heterogeneity of IT systems is more likely to arise when the same facility or campus serves different customers, as different customers may have different systems and may want the 3PL to use their system. Conversely, IT resources are more likely to be shared when different product types of the same customer are brought together, as shown by cases 2 and 3 .

Another factor that influences the possibility of sharing resources among product-customer combinations brought together within the same facility or campus is the inclusion of distribution in the service supplied by the 3PL. In cases 2, 3 and 7, the 3PL provides all product-customer combinations a global service including distribution. Consequently, the company in charge of distribution is the same for all product-customer combinations and, whenever delivery points overlap, transport network is shared. On the contrary, in cases 1, 5 and 6, the 3PL does not provide distribution. Therefore, even when different product-customer combinations served within the same facility have overlapping delivery points, opportunities for sharing of trucks are lost because the carriers taking charge of finished goods transport are different.

A final challenge in platform approach implementation is to establish appropriate coordination mechanisms to re-allocate resources among product-customer combinations. Resource-sharing gives rise to reciprocal interdependence among different product-customer combinations. Therefore, mutual adjustment, defined as the transmission of new information during the process of action (Thompson 1967), is likely to be needed to manage such dependencies. In case 6, for example, there is one supervisor for each customer served at the facility, and each supervisor communicates with the operations manager whenever workloads for the corresponding customer are lower or higher than expected. The operations manager then adjusts the number of people assigned to each product-customer combination, diverting workers from the customers with temporary excessive capacity to the customers with insufficient capacity. In this case, sharing of workforce cannot rely on the establishment of a common schedule for the interdependent product-customer combinations, as different 3PL customers have different planning routines and transmit orders at different times during the day. Even when

http://mc.manuscriptcentral.com/tprs Email: ijpr@lboro.ac.uk 
resource-sharing involves different products of the same customer and the same IT system is used for all these products, differences in planning routines may hinder aggregate planning (cases 2 and 3) and, therefore, the need for lateral relations and mutual adjustment arises.

Integrating the above arguments concerning challenges facing a 3PL in implementation of the platform approach, we make the following observation.

Observation 3. The use of the platform approach to serve a given set of product-customer combinations is enabled by:

- similarity of workforce training requirements among the product-customer combinations (3a),

- similarity of equipment requirements among the product-customer combinations (3b),

- similarity of IT systems among the product-customer combinations $\mathbf{( 3 c ) ,}$

- dissimilarity of target markets among the product-customer combinations, meaning that the combinations are not in direct competition and have complementary demand patterns (3d),

- provision of a distribution-included service to the product-customer combinations (3e),

- reliance on coordination by mutual adjustment among the productcustomer combinations (3f).

\section{Discussion and conclusions}

The present study contributes to a better understanding of the potential benefits of 3PL-provided FP services by developing a framework that links FP service type, FP service value for the 3PL's customer, FP service organisational approach, and resource-sharing enablers (Figure 6).

Insert Figure 6

This framework distinguishes different types of FP service, which have the potential to create value for the 3PL's customer through different mechanisms. On the one hand, existingPDA FP services may enable the 3PL's customer to improve its operational and financial performance in serving geographical markets that the 3PL's customer was already supplying. In this case, the FP service does not necessarily lead to market advantages for the company buying the service. This is because, for instance, the 3PL's customer may decide not to translate its lower inventory-related costs to lower prices so as to increase sales. On the other hand, PDAenabling FP services are always aimed at producing market advantages, rather than cost savings, by making it possible for the 3PL's customer to enter and profitably serve new geographical markets.

Such a distinction extends previous research findings on the types of FP strategies and their performance implications for the company implementing FP. The extant FP literature focuses on FP strategies that concern existing PDAs and lead to improved operational performance (Forza et al. 2008). Market advantages, if any, are just a second-order outcome of the operational benefits produced by these FP strategies. Our results indicate a different type of FP strategy, which concerns new, rather than existing PDAs and which has the potential to improve company performance by producing direct market advantages, rather than by enhancing operational performance. 
Pragmatically, such a distinction has important implications for both 3PLs offering FP services and their potential customers. As regards 3PLs, they need to be ready to engage with not only logistics or supply chain directors, but also marketing directors if the main benefit of the offered FP service is to create market advantages rather than cost advantages. Likewise, potential customers should regard 3PL-provided FP services not only as a means of reducing costs, but also as a possible way to increase sales. Small and medium-sized companies, in particular, could find support for their strategies of market internationalisation and expansion. The 3PL's network could be crucial, in this case, in order to postpone the creation of the varieties targeted to the new markets to a point closer to the markets themselves. This means that smaller companies, who have been reported as using 3PL services to a lesser extent than large companies (e.g., Murphy and Poist 1998, Hong et al. 2004), might look at 3PL service offerings with greater attention in the future.

Our findings also highlight the importance of the choice of the organisational solution with which an FP service will be provided. This is because through the choice of the FP service organisational approach, a 3PL has the possibility of increasing the value of an FP strategy, as compared to the situation in which the manufacturer implements FP in-house. By leveraging its serving of multiple customers, the 3PL can resort to organisational solutions, such as the multicustomer platform or the campus-style platform, which are not viable for individual manufacturers, and these solutions may mitigate a number of possible FP disadvantages. A major drawback of FP strategies, for example, is the increase in processing costs due to the loss of manufacturing scale economies and the need for excess capacity (Yang et al. 2007, Harrison and Skipworth 2008, Forza et al. 2008). By allowing use of the same capacity for a variety of customers, a multi-customer or campus-style platform decreases the total capacity required and, therefore, alleviates the negative effect of FP on processing costs. Other possible disadvantages of FP include higher transport costs, owing to direct deliveries to customers and the subsequent loss of logistics scale economies (Yang et al. 2005b, Forza et al. 2008), and higher quality assurance costs when the postponed PDA is performed in the distribution channel (Lee and Billington 1994, Forza et al. 2008). Again, the platform approach, if viable, can mitigate these FP drawbacks by reducing dependence on temporary labour without sacrificing volume flexibility and by enabling consolidation of finished goods shipments for a variety of customers.

The potential advantages of the platform approach appear particularly appealing as markets become more turbulent and 3PL customers are less willing to pay for committed capacity. Continuing downward pressure on prices is a major trend in the 3PL industry (e.g., Lieb and Bentz 2005), as also witnessed by most of our cases. As long as product-customer combinations face sufficiently high and stable demands, this challenge can be overcome while using the adhoc approach: for example, through automation or process improvement. When environmental turbulence increases, however, enhancing efficiency is more likely to require sharing of resources among multiple product-customer combinations in order to increase flexibility while decreasing the total capacity required. Nowadays, therefore, the platform approach no longer appears as a solution for serving only small customers who do not have scales that justify ad-hoc facilities. On the contrary, today the platform approach may also be crucial in increasing the value delivered to those large customers that have been traditionally served through ad-hoc facilities.

Our results, finally, indicate a number of challenges that face a 3PL in the supplying of an FP service through the platform approach. The possibility and cost of systematically sharing resources among a given set of product-customer combinations depend on the 3PL's ability to

http://mc.manuscriptcentral.com/tprs Email: ijpr@lboro.ac.uk 
bring together, within the same facility or group of facilities, product-customer combinations with complementary demand patterns and with similar resource requirements.

Variability of resource requirements may be a major obstacle to implementation of FP platforms, especially for large 3PLs serving many different product-customer combinations. Creating FP platforms may require coping with such a massive variability, for instance through appropriate location decisions. This means that besides traditional criteria for location problems, a 3PL should also consider resource-sharing enablers when deciding where a given productcustomer combination will be served. This also means that organisational barriers within a 3PL organisation may have to be overcome in order to create platforms. For example, a 3PL could create an FP platform by bringing together, within the same facility, product-customer combinations that belong to different industries, and as such are under the responsibility of different business units within the 3PL organisation, but have complementary demand patterns and similar resource requirements. Besides trying to cope with resource requirement variability, the 3PL should also strive to reduce such variability, seeking opportunities for increasing commonalities between the PDAs that are carried out, the machines that are used, the IT systems that are employed, etc. This could require, for instance, an increasing involvement of the 3PL in the design of the product families to which an FP service is to be provided.

The difficulty of reducing, or at least coping with, variability of resource requirements may eventually undermine the profitability of the concept of 3PL supplying FP services. The qualitative research approach adopted in this exploratory research, however, has not allowed us to investigate the conditions of economic viability of FP services from the 3PL perspective. Future research should address this issue, and this would require examining the relationships among the resource-sharing enablers identified in this study. There could be trade-offs, for instance, between increasing similarity of training and equipment requirements on the one hand, and reducing direct competition and overlapping of demand patterns on the other. Future studies could therefore be devoted to identifying which mixes of product-customer combinations, in terms of demand pattern characteristics, PDA characteristics, etc., are more advantageous to bring together in order to implement FP service platforms. In the pursuit of these research opportunities, we believe that our framework can assist by working as a conceptual model that guides the development of more detailed quantitative models (see Mitroff et al. 1974) capable of assessing the economic viability of different types of FP services in many different specific contexts. Such quantitative models would help 3PLs to understand the profitability of FP services as compared to other commonly provided services, thus supporting definition of 3PL service offering.

By showing that a 3PL may be crucial in enabling another company to implement FP or has the possibility of increasing the value of FP as compared to the situation in which the other company implements FP in-house, this study adds to past research findings in the area of interorganisational FP. In our empirical inquiry, however, we have only got data from the 3PL, and this is another limitation of the present study. Future research would definitely benefit from collecting data from 3PL customers as well. This would allow, for example, in-depth investigation of the challenges and drawbacks of using FP services from a 3PL's customer perspective, which investigation was out of the scope of our research.

\section{Acknowledgements}

This paper benefited from the many insightful comments made by two anonymous reviewers. The author is also grateful to the numerous managers of a third-party logistics provider who 
devoted their time and experience to this research, as well as to the other members of the joint research project that involved this company, the Massachusetts Institute of Technology and the Zaragoza Logistics Center. In particular, the authors would like to thank C. Forza and F. Salvador for the suggestions and support given throughout this research project.

\section{References}

Alderson, W., 1950. Marketing efficiency and the principle of postponement. Cost and Profit Outlook, 3 (4), 15-18.

Alderson, W. 1957. Marketing behavior and executive action. Homewood, IL: Richard D. Irwin Inc.

Anand, K.S. and Girotra, K., 2007. The strategic perils of delayed differentiation. Management Science, 53 (5), 697-712.

Aviv, Y. and Federgruen, A., 2001. Design for postponement: a comprehensive characterization of its benefits under unknown demand distributions. Operations Research, 49 (4), 578598.

Bayus, B.L. and Putsis, W.P., 1999. Product proliferation: an empirical analysis of product line determinants and market outcomes. Marketing Science, 18 (2), 137-153.

Brown, A.O., Lee, H.L. and Petrakian, R., 2000. Xilinx improves its semiconductor supply chain using product and process postponement. Interfaces, 30 (4), 65-80.

Bucklin, L.P., 1965. Postponement, speculation and the structure of distribution channels. Journal of Marketing Research, 2(1), 26-31.

Chiou, J.-S., Wu, L.-Y. and Hsu, J.C., 2002. The adoption of form postponement strategy in a global logistics system: the case of Taiwanese information technology industry. Journal of Business Logistics, 23 (1), 107-124.

Cooper, J.C., 1993. Logistics strategies for global businesses. International Journal of Physical Distribution and Logistics Management, 23 (4), 12-23.

Davila, T. and Wouters, M., 2007. An empirical test of inventory, service and cost benefits from a postponement strategy. International Journal of Production Research, 45 (10), 22452267.

Eisenhardt, K.M, 1989. Building Theories from Case Study Research. Academy of Management Review, 14 (4), 532-550.

Feitzinger, E. and Lee, H.L., 1997. Mass customization at Hewlett-Packard: the power of postponement. Harvard Business Review, 75 (1), 116-121.

Forza, C., Salvador, F. and Trentin, A., 2008. Form postponement effects on operational performance: a typological theory. International Journal of Operations and Production Management, 28 (11), 1067-1094.

Funke, M. and Ruhwedel, R., 2001. Product variety and economic growth: empirical evidence from the OECD countries. IMF Staff Papers, 48 (2), 225-242.

García-Dastugue, S. and Lambert, D.M., 2007. Interorganizational time-based postponement in the supply chain. Journal of Business Logistics, 28 (1), 57-81.

Garg, A. and Tang, C.S., 1997. On postponement strategies for product families with multiple points of differentiation. IIE Transactions, 29 (8), 641-650.

Gupta, D. and Benjaafar, S., 2004. Make-to-order, make-to-stock, or delay product differentiation? A common framework for modeling and analysis. IIE Transactions, 36 (6), 529-546. 
Gupta, S. and Krishnan, V., 1998. Product family-based assembly sequence design methodology. IIE Transactions, 30 (10), 933-945.

Harrison, A. and Skipworth, H., 2008. Implications of form postponement to manufacturing: a cross case comparison. International Journal of Production Research, 46 (1), 173-195.

Heskett, J.L, 1977. Logistics - essential to strategy. Harvard Business Review, 55 (6), 119-126.

Hong, J., Chin, A.T.H. and Liu, B., 2004. Logistics outsourcing by manufacturers in China: a survey of the industry. Transportation Journal, 43 (1), 17-25.

Johnson, E.M. and Anderson, E., 2000. Postponement strategies for channel derivatives. The International Journal of Logistics Management, 11 (1), 19-35.

Krajewski, L., Wei, J.C. and Tang, L.-L., 2005. Responding to schedule changes in build-toorder supply chains. Journal of Operations Management, 23 (5), 452-469.

Kumar, S. and Wilson, J., 2009. A manufacturing decision framework for minimizing inventory costs of a configurable off-shored product using postponement. International Journal of Production Research, 47 (1), 143-162.

Lee, H.L, 1996. Effective inventory and service management through product and process redesign. Operations Research, 44 (1), 151-159.

Lee, H.L. and Billington, C., 1994. Designing products and processes for postponement. In: S. Dasu and C. Eastman, eds. Management of design: engineering and management perspectives. Boston, MA: Kluwer, 105-122.

Lee, H.L. and Tang, C.S., 1997. Modelling the costs and benefits of delayed product differentiation. Management Science, 43 (1), 40-53.

Lee, H.L., Billington, C. and Carter, B., 1993. Hewlett-Packard gains control of inventory and service through design for localization. Interfaces, 23 (4), 1-11.

Lieb, R. and Bentz, B.A., 2005. The North American third party logistics industry in 2004: the provider CEO perspective. International Journal of Physical Distribution and Logistics Management, 35 (8), 595-611.

Marasco, A., 2008. Third-party logistics: a literature review. International Journal of Production Economics, 113 (1), 127-47.

Matthews, P. and Syed, N., 2004. The power of postponement. Supply Chain Management Review, 8 (3), 28-34.

Mitroff, I.I., Betz, F., Pondy, L.R. and Sagasti, F., 1974. On managing science in the systems age: two schemas for the study of science as a whole systems phenomenon. Interfaces, 4 (3), 46-58.

Murphy, P.R. and Poist, R.F., 1998. Third-party logistics usage: an assessment of propositions based on previous research. Transportation Journal, 37 (4), 26-35.

Pagh, J.D. and Cooper, M.C., 1998. Supply chain postponement and speculation strategies: how to choose the right strategy. Journal of Business Logistics, 19 (2), 13-33.

Patton, M.Q., 1990. Qualitative evaluation and research methods. Newbury Park, CA: Sage Publications.

Pine, J.B.II, 1993. Mass Customization - The New Frontier in Business Competition. Boston, MA: Harvard Business School Press.

Prasad, S., Tata, J. and Madan, M., 2005. Build to order supply chains in developed and developing countries. Journal of Operations Management, 23 (5), 551-568.

Selviaridis, K.and Spring, M., 2007. Third party logistics: a literature review and research agenda. The International Journal of Logistics Management, 18 (1), 125-50. 
Shao, X.-F. and Ji, J.-H., 2008. Evaluation of postponement strategies in mass customization with service guarantees. International Journal of Production Research, 46 (1), 153-171.

Strauss, A.L., 1987. Qualitative analysis for social scientists. Cambridge, UK: Cambridge University Press.

Swaminathan, J.M. and Lee, H.L., 2003. Design for postponement. In: S.C. Graves and A.G. de Kok, eds. Supply chain management: design, coordination and operation - Handbooks in OR/MS, Vol. 11. Amsterdam, The Netherlands: Elsevier Publishers, 199-228.

Thompson, J.D., 1967. Organizations in action. New York, NY: McGraw-Hill.

Twede, D., Clarke, R.H. and Tait, J.A., 2000. Packaging postponement: a global packaging strategy. Packaging Technology and Science, 13 (3), 105-115.

van Hoek, R.I., 1997. Postponed manufacturing: a case study in the food supply chain. Supply Chain Management, 2 (2), 63-75.

van Hoek, R.I., 1998. Reconfiguring the supply chain to implement postponed manufacturing. The International Journal of Logistics Management, 9 (1), 95-110.

van Hoek, R.I., 2000a. Role of third party logistic services in customization through postponement. International Journal of Service Industry Management, 11 (4), 374-87.

van Hoek, R.I., 2000b. The purchasing and control of supplementary third-party logistics services. The Journal of Supply Chain Management: A Global Review of Purchasing and Supply, 36 (4), 14-26.

van Hoek, R.I., 2001. The rediscovery of postponement: a literature review and directions for research. Journal of Operations Management, 19 (2), 161-84.

van Hoek, R.I., Commandeur, H.R. and Vos, B., 1998. Reconfiguring logistics systems through postponement strategies. Journal of Business Logistics, 19 (1), 33-54.

van Hoek, R.I. and van Dierdonck, R., 2000. Postponed manufacturing supplementary to transportation services? Logistics and Transportation Review, 36 (3), 205-16.

Voss, C., Tsikriktsis, N. and Frohlich, M., 2002. Case research in operations management. International Journal of Operations and Production Management, 22 (2), 195-219.

Wong, H., Wikner, J. and Naim, M., 2009. Analysis of form postponement based on optimal positioning of the differentiation point and stocking decisions. International Journal of Production Research, 47 (5), 1201-1224.

Yang, B. and Burns, N.D., 2003. Implications of postponement for the supply chain. International Journal of Production Research, 41 (9), 2075-2090.

Yang, B., Burns, N.D. and Backhouse, C.J., 2004a. Management of uncertainty through postponement. International Journal of Production Research, 42 (6), 1049-1064.

Yang, B., Burns, N.D. and Backhouse, C.J., 2004b. Postponement: a review and an integrated framework. International Journal of Operations and Production Management, 24 (5), 468-487.

Yang, B., Burns, N.D. and Backhouse, C.J., 2005a. An empirical investigation into the barriers to postponement. International Journal of Production Research, 43 (5), 991-1005.

Yang, B., Yang, Y. and Wijngaard, J., 2005b. Impact of postponement on transport: an environmental perspective. The International Journal of Logistics Management, 16 (2), 192-204.

Yang, B., Yang, Y. and Wijngaard, J., 2007. Postponement: an inter-organizational perspective. International Journal of Production Research, 45 (4), 971-988. 
Yeung, J.H.Y., Selen, W., Deming, Z. and Min, Z., 2007. Postponement strategy from a supply chain perspective: cases from China. International Journal of Physical Distribution and Logistics Management, 37 (4), 331-356.

Yin, R.K., 1984. Case study research: design and methods. Beverly Hills, CA: Sage Publications.

Zinn, W, 1990. Developing heuristics to estimate the impact of postponement on safety stock. The International Journal of Logistics Management, 1 (2), 11-16.

Zinn, W. and Bowersox, D.J., 1988. Planning physical distribution with the principle of postponement. Journal of Business Logistics, 9 (2), 117-36. 
Table 1. Description of the selected cases and data sources.

\begin{tabular}{|c|c|c|c|c|c|}
\hline Case & Industry & $\begin{array}{l}\text { ISIC } \\
\text { code }\end{array}$ & $\begin{array}{l}\mathrm{PDA}(\mathrm{s}) \text { performed by the } 3 \mathrm{PL} \\
\text { in the distribution channel }\end{array}$ & PDA(s) description & Main data sources \\
\hline 1 & Electronics & 2817 & Kitting of calculators & $\begin{array}{l}\text { The same calculator may be packed together with different or } \\
\text { optional components, such as manuals, cables, marketing } \\
\text { leaflets etc., according to the country/market of destination } \\
\text { (from } 6 \text { to } 20 \text { components per kit). Different possible types of } \\
\text { packaging, such as cardboard boxes, pizza-style boxes or } \\
\text { clamshells, may be used. }\end{array}$ & $\begin{array}{l}\text { Contract operations manager } \\
\text { interviews (2) } \\
\text { Facility visits (2) } \\
\text { Archival documents }\end{array}$ \\
\hline 2 & Electronics & 2620 & Kitting of consumer printers & $\begin{array}{l}\text { The same printer may be localised by adding different } \\
\text { components, such as power supply cables, manuals, stickers, } \\
\text { etc., according to the country/market of destination. Further, } \\
\text { customer-specific components, such as retailer-specific labels, } \\
\text { may be added. }\end{array}$ & $\begin{array}{c}\text { Program manager interviews (2) } \\
\text { Facility visits (2) } \\
\text { Archival documents }\end{array}$ \\
\hline 3 & Electronics & 2620 & $\begin{array}{l}\text { Hardware and software } \\
\text { configuration of point-of-sale } \\
\text { terminals }\end{array}$ & $\begin{array}{l}\text { A generic point-of-sale (PoS) terminal may be custom- } \\
\text { configured (e.g., memory upgrade, Ethernet card to be } \\
\text { included, software installation and firmware upgrade) just } \\
\text { prior to dispatch of the finished product to the customer. }\end{array}$ & $\begin{array}{c}\text { Program manager interviews (2) } \\
\text { Facility visits (2) } \\
\text { Archival documents }\end{array}$ \\
\hline 4 & Personal care & 2023 & $\begin{array}{l}\text { Co-packing of personal-care } \\
\text { products }\end{array}$ & $\begin{array}{l}\text { The same personal-care product may be packed together with } \\
\text { different gifts according to the promotion conception. }\end{array}$ & $\begin{array}{l}\text { Contract packing manager } \\
\text { interviews (2) } \\
\text { Facility visit } \\
\text { Archival documents }\end{array}$ \\
\hline 5 & Telecommunications & 6120 & Kitting of phone packs & $\begin{array}{l}\text { Different phone packs may be created by putting together, in a } \\
\text { transparent box, different mobile phone handsets, subscriber } \\
\text { identity module cards, marketing leaflets, promotional } \\
\text { materials, etc. according to the promotion conception (average } \\
\text { components per kit: } 15 \text { ). }\end{array}$ & $\begin{array}{l}\text { Business unit director interview } \\
\text { Operations manager interview } \\
\text { Facility visit } \\
\text { Archival documents }\end{array}$ \\
\hline 6 & Pharmaceuticals & 2100 & $\begin{array}{l}\text { Building displays of over-the- } \\
\text { counter products }\end{array}$ & $\begin{array}{l}\text { Different displays of different over-the-counter (OTC) } \\
\text { products for pharmacies may be created according to the } \\
\text { promotion conception. }\end{array}$ & $\begin{array}{l}\text { General manager interview } \\
\text { Facility visit } \\
\text { Archival documents }\end{array}$ \\
\hline 7 & Pharmaceuticals & 2100 & $\begin{array}{l}\text { Labelling and packaging of } \\
\text { medicines for treatment of } \\
\text { life-threatening diseases }\end{array}$ & $\begin{array}{c}\text { Country-specific labels and literature (27 country variants / } 24 \\
\text { languages) are added to four strengths of one medication, } \\
\text { which is to arrive at the 3PL's facility without label and blank } \\
\text { carton. }\end{array}$ & $\begin{array}{l}\text { Product development healthcare } \\
\text { manager interviews (2) } \\
\text { Site visit } \\
\text { Archival documents }\end{array}$ \\
\hline
\end{tabular}


Table 2. FP services provided in the selected cases and value delivered to the 3PL's customer.

\begin{tabular}{|c|c|c|c|}
\hline Case & FP service & Value to the customer & Explanation \\
\hline 2 & $\begin{array}{l}\text { Existing- } \\
\text { PDA }\end{array}$ & $\begin{array}{l}\text { Improved operational } \\
\text { and financial } \\
\text { performance in serving } \\
\text { existing geographical } \\
\text { markets }\end{array}$ & $\begin{array}{l}\text { The risks and associated costs of producing the wrong mix of printer variants are eliminated, as the customer no longer holds } \\
\text { speculative stock of finished goods. Close-to-the-market specification of goods guarantees short delivery lead-times ( } 1 \text { day) } \\
\text { and enhances responsiveness to varying demand in different countries, especially when launching or phasing out models. } \\
\text { Fixed asset investment is reduced. Overhead decrease and volume flexibility increases because of one-stop-shop for all FP } \\
\text { services provided to the customer. }\end{array}$ \\
\hline 1 & $\begin{array}{l}\text { Existing- } \\
\text { PDA }\end{array}$ & $\begin{array}{l}\text { Improved operational } \\
\text { and financial } \\
\text { performance in serving } \\
\text { existing geographical } \\
\text { markets }\end{array}$ & $\begin{array}{l}\text { Speculative stock of high-value products is reduced while preserving on-hand availability of finished goods, as calculators are } \\
\text { packed at a time closer to the moment of customer purchase and, hence, demand mix uncertainty is lower. Rework costs of } \\
\text { leftover stock decrease, as the risk of overestimating a county's demand is lower. Lead-times in responding to unanticipated } \\
\text { market requirements are shortened without using faster modes of transport. Investment in fixed assets is reduced. Overhead } \\
\text { decrease due to resource-sharing among multiple product-customer combinations. }\end{array}$ \\
\hline 4 & $\begin{array}{l}\text { Existing- } \\
\text { PDA }\end{array}$ & $\begin{array}{l}\text { Improved operational } \\
\text { and financial } \\
\text { performance in serving } \\
\text { existing geographical } \\
\text { markets }\end{array}$ & $\begin{array}{l}\text { The undifferentiated personal-care product is held in a location closer to the customer and is co-packed at a time closer to the } \\
\text { promotional launch. As the promotion conception and sales forecast generation occur closer to the time when market demand } \\
\text { is observed, there is less speculative stock and rework costs of leftover decrease. Lead-times in responding to unanticipated } \\
\text { market conditions are shortened without use of faster modes of transport. Indirect operating costs decrease because of } \\
\text { reduction in factory complexity. Investment in fixed asset is lower. Transport costs are reduced, as the undifferentiated } \\
\text { product being shipped from the factory to the distribution centre is less bulky. }\end{array}$ \\
\hline 3 & $\begin{array}{l}\text { Existing- } \\
\text { PDA }\end{array}$ & $\begin{array}{l}\text { Improved operational } \\
\text { and financial } \\
\text { performance in serving } \\
\text { existing geographical } \\
\text { markets }\end{array}$ & $\begin{array}{l}\text { PoS terminals are configured in a location closer to the market. Therefore, the customers can fully specify the product they } \\
\text { need at a time closer to product delivery, when they have more information about the product features that will maximise their } \\
\text { utility. Further, time and cost performance are not impaired by late order specification. Investment in fixed assets is reduced. } \\
\text { Overhead decrease and capacity utilisation increases because of one-stop-shop for all FP services provided to the customer. } \\
\text { Distribution costs are lower due to overlapping of delivery points for different product families of the same customer. }\end{array}$ \\
\hline 5 & $\begin{array}{l}\text { PDA- } \\
\text { enabling }\end{array}$ & $\begin{array}{l}\text { Entry into a new } \\
\text { geographical market }\end{array}$ & $\begin{array}{l}\text { Serving the new market requires carrying out kitting activities to create different phone packs according to the promotion } \\
\text { conception. However, the 3PL's customer would not carry out manufacturing activities in-house because of its focus on the } \\
\text { development and commercialisation of mobile telecommunications services. Phone packs are built in a location close to the } \\
\text { market and, hence, at a time close to the promotional launch. Consequently, inventory-holding costs are low and reaction time } \\
\text { on market demand is fast. Investment in fixed assets is reduced. }\end{array}$ \\
\hline 6 & $\begin{array}{l}\text { PDA- } \\
\text { enabling }\end{array}$ & $\begin{array}{l}\text { Entry into a new } \\
\text { geographical market }\end{array}$ & $\begin{array}{l}\text { Serving the new market requires building different displays of OTC medicines for pharmacies according to the promotion } \\
\text { conception. However, the 3PL's customer is a fabless company focused on the development and commercialisation of OTC } \\
\text { products and would not carry out such activity in-house. As displays are built in a location close to the market, inventory- } \\
\text { holding costs are low and lead-times in responding to unanticipated market conditions are short. Fixed asset investment is } \\
\text { reduced. Overhead and operating costs are low due to resource-sharing among multiple product-customer combinations. }\end{array}$ \\
\hline 7 & $\begin{array}{l}\text { PDA- } \\
\text { enabling }\end{array}$ & $\begin{array}{c}\text { Entry into new } \\
\text { geographical markets }\end{array}$ & $\begin{array}{l}\text { Serving the new markets in Europe requires adding different labels and literature to the medication according to the country of } \\
\text { destination. The 3PL's customer, however, is a small US-based biotech company and could not profitably create these product } \\
\text { variants at its laboratories, owing to the high risks and associated costs of keeping speculative inventory of finished goods. } \\
\text { Likewise, the company could not set up a facility to create these variants in Europe because of its scale. Close-to-the-market } \\
\text { labelling and packaging based upon market demand lead to little inventory waste, low rework costs and great responsiveness } \\
\text { to specific country trends or regulatory change. Overhead, processing costs and distribution costs are low due to resource- } \\
\text { sharing among multiple product-customer combinations. The 3PL handles certified translation of labels and provides a single } \\
\text { point of contact for component approval in each country, thus simplifying the process for the customer. }\end{array}$ \\
\hline
\end{tabular}

http://mc.manuscriptcentral.com/tprs Email: ijpr@lboro.ac.uk 
Table 3. Organisational approaches adopted in the selected cases to provide FP services, effects on customer value, and implementation challenges.

\begin{tabular}{|c|c|c|c|}
\hline Case & Organisational approach & (Lack of) resource-sharing (dis)advantages & Resource-sharing enablers (obstacles) \\
\hline 5 & $\begin{array}{l}\text { The facility is dedicated to } \\
\text { case } 4\end{array}$ & $\begin{array}{c}\text { (Capacity underutilisation) } \\
\text { (8 assembly lines, but only } 2 \text { of them are used out } \\
\text { of peak periods) } \\
(\text { Dependence on temporary labour }) \\
\text { (up to } 100 \text { temporary workers in peak periods. } \\
\text { Lower productivity due to learning curves. } \\
\text { Temporary labour sometimes difficult to find) }\end{array}$ & $\begin{array}{c}\text { (Customers serving the same market) } \\
\text { (the customer would not allow resource-sharing with direct competitors, owing to } \\
\text { confidential information related to promotions) } \\
\text { (Distribution not included in the service) } \\
\text { (distribution provided by another 3PL operating in the local market) }\end{array}$ \\
\hline 4 & $\begin{array}{l}\text { The facility is dedicated to } \\
\text { case } 5\end{array}$ & $\begin{array}{l}(\text { Capacity underutilisation }) \\
\text { (7 assembly lines, but only } 3 \text { of them are used out } \\
\text { of peak periods) } \\
\text { (Dependence on temporary labour })\end{array}$ & $\begin{array}{l}\text { (Customers serving the same market) } \\
\text { (the customer would not allow resource-sharing with direct competitors, owing to } \\
\text { confidential information related to promotions) }\end{array}$ \\
\hline 1 & $\begin{array}{l}\frac{A d-h o c}{\text { The facility is divided in six }} \\
\text { compartments for six } \\
\text { customers operating mainly } \\
\text { in the semiconductor } \\
\text { industry. They are provided } \\
\text { both logistics and value- } \\
\text { added services, but PDAs } \\
\text { are performed for case } 1 \\
\text { alone }\end{array}$ & 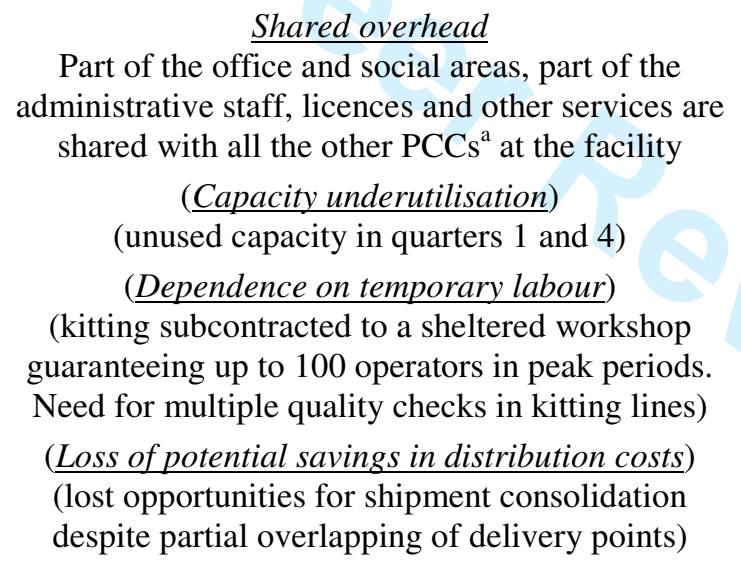 & $\begin{array}{l}\text { (Heterogeneity of IT systems) } \\
\text { (the IT system used for case } 1 \text { is customer's property and is different from those } \\
\text { used for the other PCCs }{ }^{\mathrm{a}} \text { served at the facility) } \\
\text { (Heterogeneity of training and equipment requirements) } \\
\text { (no VAS operators are shared with the other PCCs }{ }^{\mathrm{a}} \text { served at the facility, owing } \\
\text { to different training requirements and high costs of cross-training. Sealing } \\
\text { machines are specific to kitting activities and cannot be shared with the other } \\
\text { PCCs }{ }^{\mathrm{a}} \text { served at the facility) } \\
\text { (Distribution not included in the service) } \\
\text { (the customer performs all distribution management on its own and decides } \\
\text { which transport to take from which 3PL) }\end{array}$ \\
\hline 2 & $\begin{array}{l}\text { Multi-product platform } \\
\text { The facility currently serves } \\
\text { two product families of the } \\
\text { same customer: case } 2 \text { and } \\
\text { case } 3 \text {. In the future, the } \\
\text { facility will serve a third } \\
\text { product family of the same } \\
\text { customer-business printers- } \\
\text { which require performance } \\
\text { of localisation and technical } \\
\text { configuration activities }\end{array}$ & 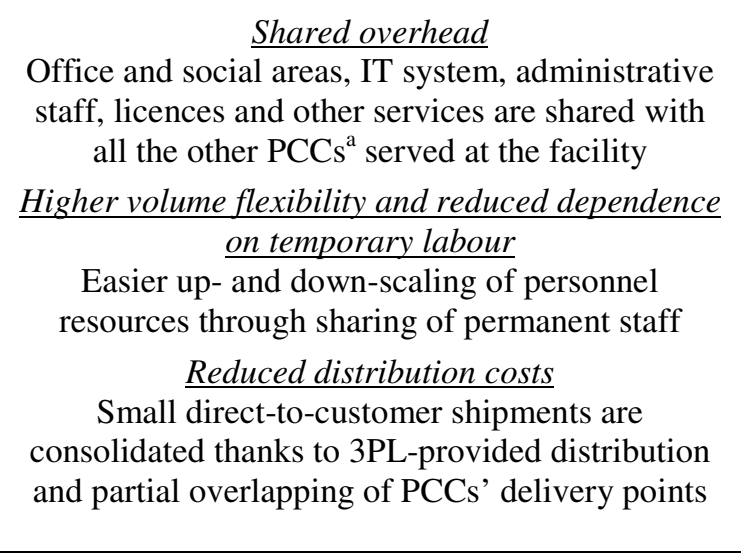 & $\begin{array}{l}\text { (Heterogeneity of training requirements) } \\
\text { (configuration of PoS terminals-case 3-requires highly skilled workers, while } \\
\text { kitting of consumer printers-case 2-does not. Due to the high costs of cross } \\
\text { training, VAS operators for case } 3 \text { can be employed for case 2, but not vice versa. } \\
\text { More sharing of workforce is expected with the coming of business printers) } \\
\text { (Heterogeneity of equipment requirements) } \\
\text { (VAS equipment and areas not shared, as configuration of PoS terminals needs to } \\
\text { be done in a semi-clean environment with safety regulations) } \\
\text { Coordination by mutual adjustment } \\
\text { Coordination by aggregate planning is hindered by the fact that the 3PL has } 5 \\
\text { days of visibility over the customer's delivery schedule for PoS terminals, but } \\
\text { only } 1 \text { day for consumer printers } \\
\text { (continued) }\end{array}$ \\
\hline
\end{tabular}

http://mc.manuscriptcentral.cóm/tprs Email: ijpr@lboro.ac.uk 


\begin{tabular}{cc}
\hline Case & Organisational approach \\
\hline 3 & Multi-product platform \\
The facility currently serves \\
two product families of the \\
same customer: case 2 and \\
case 3 . In the future, the \\
facility will serve a third \\
product family of the same \\
customer-business printers- \\
which require performance \\
of localisation and technical \\
configuration activities
\end{tabular}

$6 \quad$ Multi-customer platform

The facility provides

logistics services to seven customers operating in the pharmaceutical industry and value-added services to three of them. However, a PDA is carried out for case 6 alone

$7 \quad$ Campus-style platform 35 customers in the pharmaceuticals, medical devices and hospitals industries are served in three facilities close to each other. The customers are provided both logistics and valueadded services. PDAs are carried out for case 7 and another $\mathrm{PCC}^{\mathrm{a}}$ requiring assembly of different surgical kits

\section{(Lack of) resource-sharing (dis)advantages}

Higher capacity utilisation and shared overhead

Office and social areas, IT system, workforce, administrative staff, licences and other services are

shared with all the other PCCs ${ }^{\mathrm{a}}$ served at the facility

\section{Reduced distribution costs}

The 3PL also provides distribution services and delivery points partially overlap among the PCCs served at the facility. Therefore, small shipments

dispatched directly to the customers are consolidated

\section{Higher capacity utilisation and shared overhead}

Facility, equipment, workforce, part of the administrative staff, licences and other services are shared with all the other PCCs ${ }^{\mathrm{a}}$ at the facility

$$
\text { Higher volume flexibility }
$$

Workforce for a single customer can be increased up to $50 \%$ from one day to the next through sharing of permanent staff

Reduced dependence on temporary labour

All workers are permanent employees, except in

July. This is the only period in which demand

peaks for the PCCs ${ }^{\text {a }}$ served at the facility overlap. Demand patterns are for the most part complementary, as the customers serve different markets: hospitals and pharmacies

Higher capacity utilisation and shared overhead Inbound/storage/outbound areas, VAS areas, office and social areas, material handling and VAS equipment, workforce, IT system, administrative staff, licences and other services are shared among different PCCs ${ }^{\mathrm{a}}$ served within the campus

Reduced dependence on temporary labour All workers are permanent employees

\section{Reduced distribution costs}

The 3PL also provides distribution services and consolidates small shipments, thanks to partial overlapping of delivery points among the $\mathrm{PCCs}^{\mathrm{a}}$
Resource-sharing enablers (obstacles)

\section{(Heterogeneity of training requirements)}

(configuration of PoS terminals-case 3-requires highly skilled workers, while kitting of consumer printers-case 2-does not. Due to the high costs of cross training, VAS operators for case 3 can be employed for case 2, but not vice versa. More sharing of workforce is expected with the coming of business printers)

\section{(Heterogeneity of equipment requirements)}

(VAS equipment and areas not shared, as configuration of PoS terminals needs to be done in a semi-clean environment with safety regulations)

Coordination by mutual adjustment

Coordination by aggregate planning is hindered by the fact that the 3PL has 5 days of visibility over the customer's delivery schedule for PoS terminals, but only 1 day for consumer printers

\section{(Heterogeneity of IT systems)}

(the IT system used for case 6 is customer's property and is common to only two $\mathrm{PCCs}^{\mathrm{a}}$ at the facility. Three different, either customer-owned or 3PL-owned, IT systems are used at the facility, with subsequent duplication of IT staff)

\section{(Heterogeneity of training requirements)}

(though products are similar, cross-training of workforce is needed because of different processes and procedures among the PCCs ${ }^{\mathrm{a}}$ served at the facility. IT staff is cross-trained as well, owing to the use of different IT systems)

\section{(Distribution not included in the service)}

(distribution provided by two small transport companies operating in the local market)

\section{Coordination by mutual adjustment}

Need for mutual adjustments between the supervisors in charge of each customer's operations, as the customers have different planning routines and place delivery orders on a daily basis but at different points in time

(Heterogeneity of training and equipment requirements and IT systems) (Clinical trial customers have a few dedicated resources-storage/outbound areas, equipment, workforce, part of the administrative staff, licences, customer service-due to specific regulations and laws that are different from normal pharmaceuticals. Likewise, another $\mathrm{PCC}^{\mathrm{a}}$ has a few dedicated resourcesinbound/storage/outbound areas, VAS area and equipment, workforce-because customer-specific IT system, processes and procedures, and training are needed in order to work with a very large amount of stock-keeping units-7500 possible end items)

\section{Coordination by mutual adjustment}

Mutual adjustments between resource planners of different customer are needed, as the customers have different planning routines 


\section{Figure captions}

Figure 1. Existing-PDA (from-forecast-to-order-driven-PDA) FP service.

Figure 2. Existing-PDA (remaining-forecast-driven-PDA) FP service.

Figure 3. Existing-PDA (remaining-order-driven-PDA) FP service.

Figure 4. PDA-enabling FP service.

Figure 5. Organisational approaches adopted in the selected cases to provide FP services.

Figure 6. The proposed framework linking FP service type, customer value, organisational approach and resource-sharing enablers. 


\title{
SUPPLY CHAIN CONFIGURATION BEFORE FP SERVICE ${ }^{a}$
}

- PDA performed by the manufacturer at a factory

on a to-forecast basis

\section{SUPPLY CHAIN CONFIGURATION AFTER FP SERVICE \\ - PDA performed by the 3PL in the distribution channel based on the order-driven master production schedule created by the manufacturer}

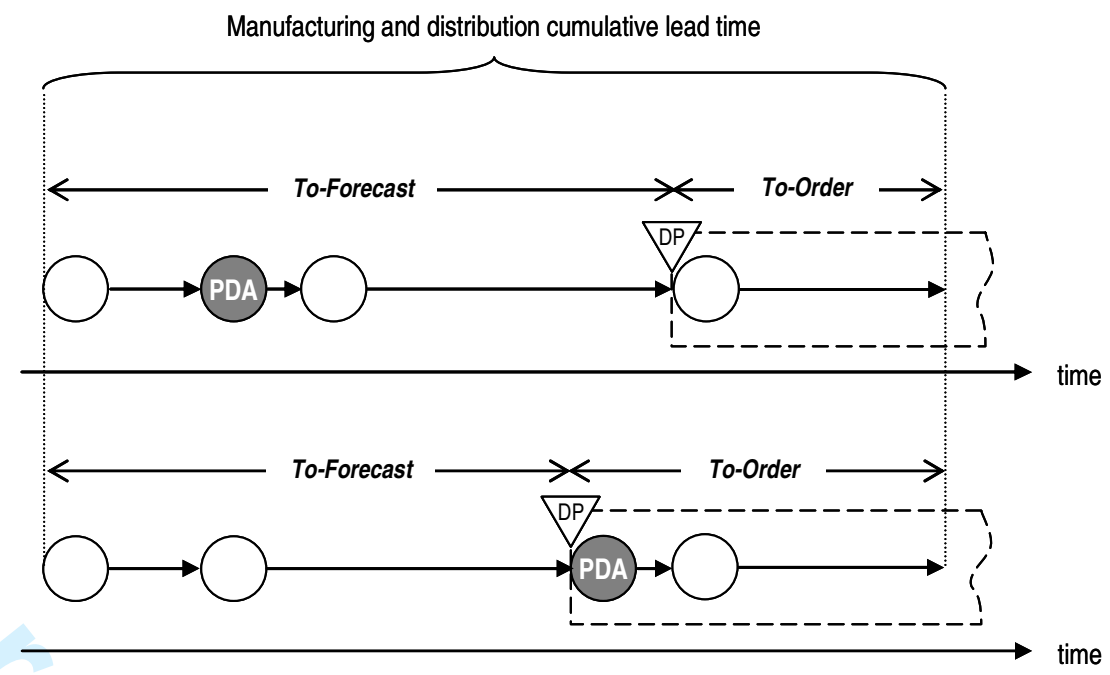

Key:
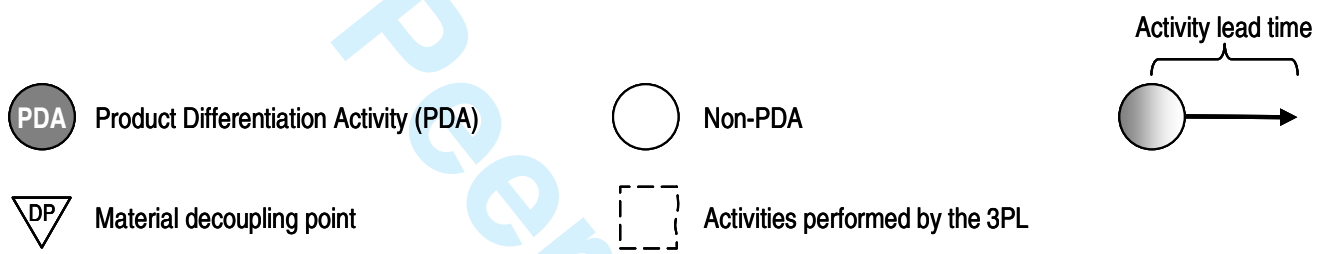

$$
\text { Key: }
$$

Material decoupling point

Figure 1. Existing-PDA (from-forecast-to-order-driven-PDA) FP service.

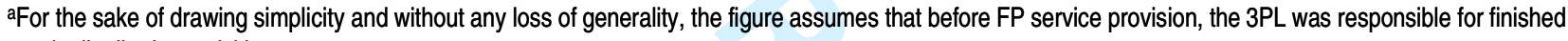
goods distribution activities.
\end{abstract}




\title{
SUPPLY CHAIN CONFIGURATION
} BEFORE FP SERVICE ${ }^{\mathrm{a}}$

- PDA performed by the manufacturer at a factory

on a to-forecast basis

\section{SUPPLY CHAIN CONFIGURATION}

\section{AFTER FP SERVICE}

- PDA performed by the 3PL in the distribution channel based on the forecast-driven master production schedule created by the manufacturer

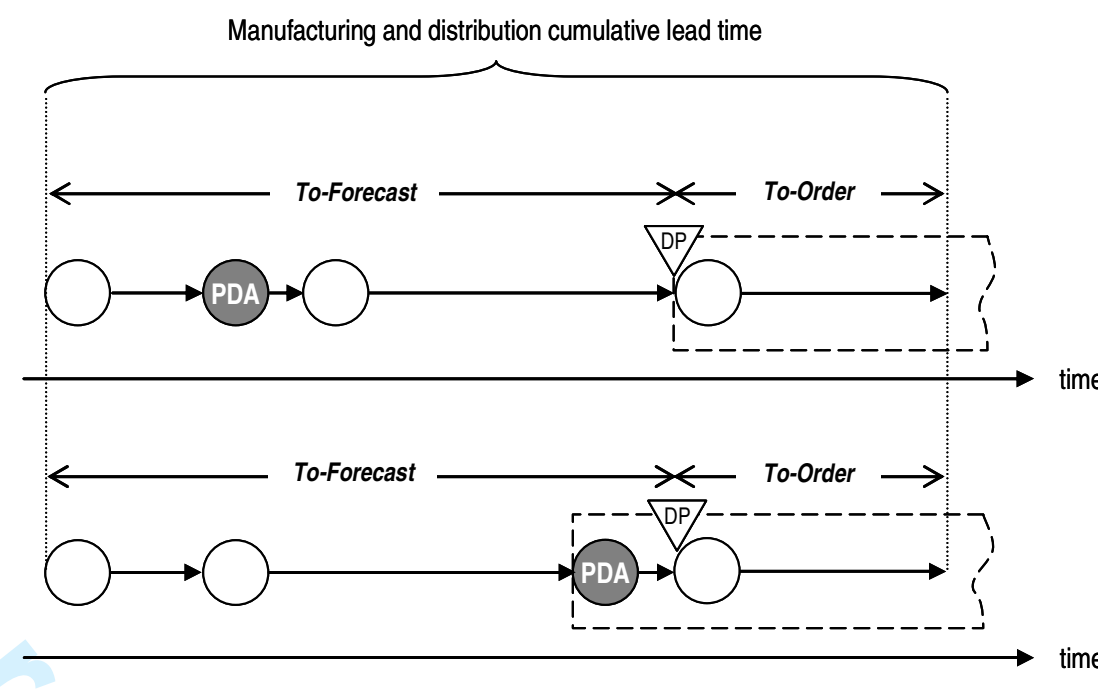

Key:

PDA) Product Differentiation Activity (PDA)
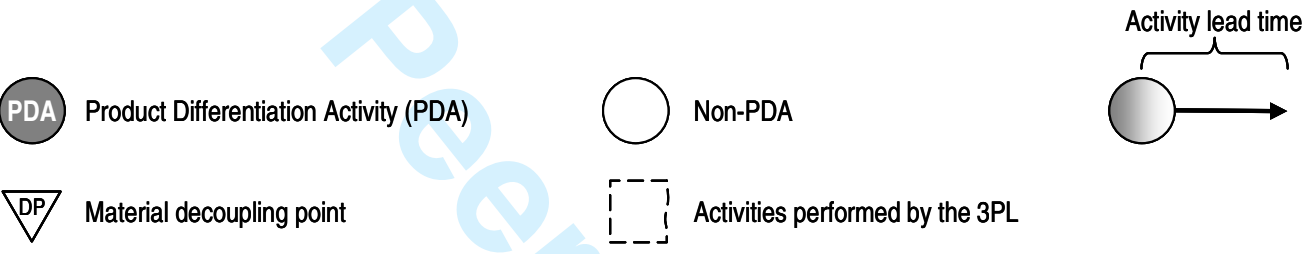

\begin{abstract}
aFor the sake of drawing simplicity and without any loss of generality, the figure assumes that before FP service provision, the 3PL was responsible for finished goods distribution activities.
\end{abstract}

Figure 2. Existing-PDA (remaining-forecast-driven-PDA) FP service. 


\begin{abstract}
aFor the sake of drawing simplicity and without any loss of generality, the figure assumes that before FP service provision, the 3PL was responsible for finished goods distribution activities
\end{abstract}

Figure 3. Existing-PDA (remaining-order-driven-PDA) FP service.

Activity lead time

Key:
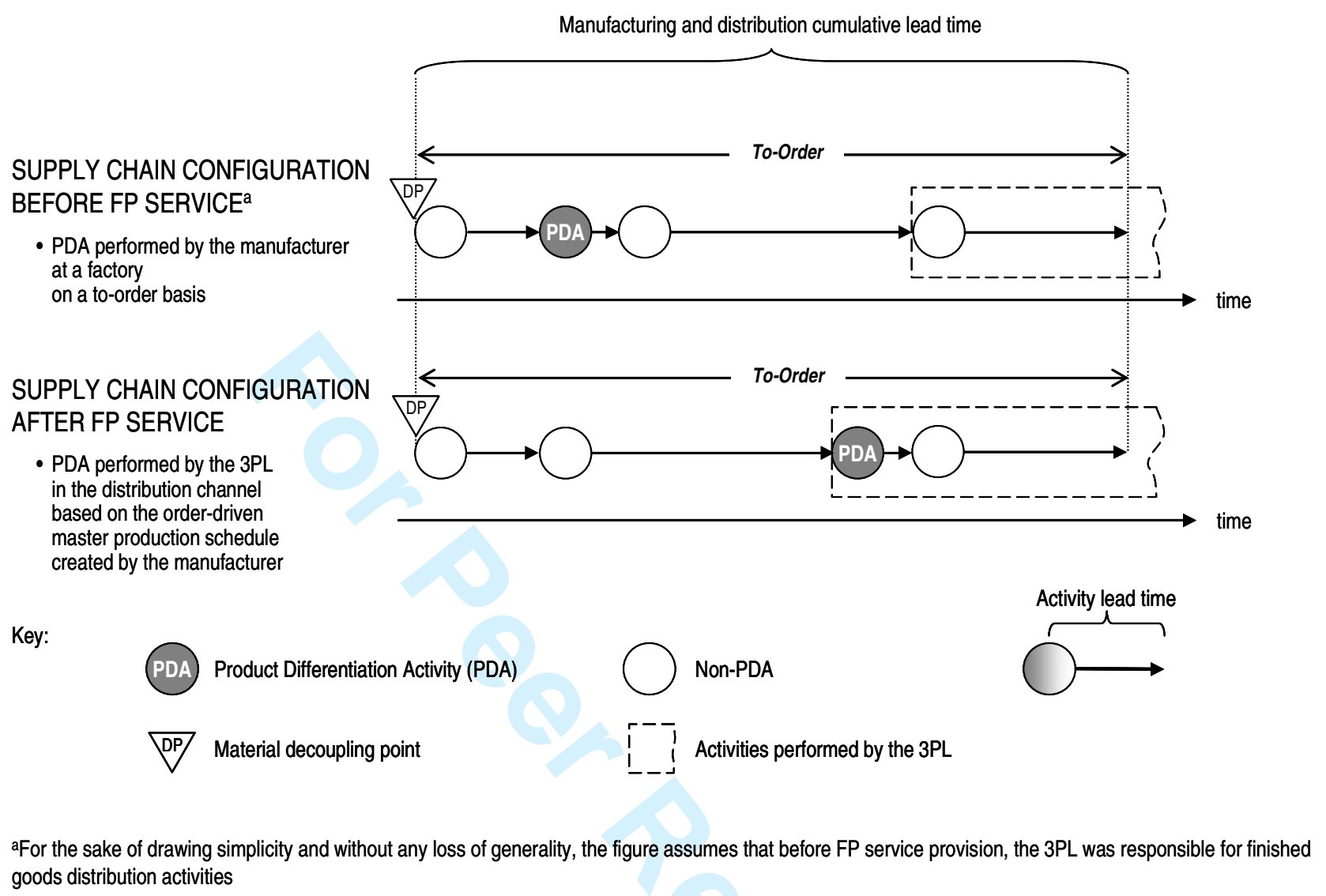

DP Material decoupling point

I Activities performed by the 3PL 


\begin{abstract}
aFor the sake of drawing simplicity and without any loss of generality, the figure assumes that before FP service provision, the 3PL was responsible for finished goods distribution activities.
\end{abstract}

Figure 4. PDA-enabling FP service. 


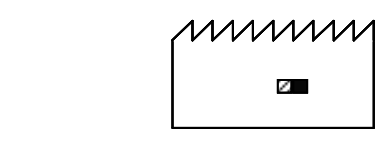

AD-HOC FACILITY

resources dedicated to a single productcustomer combination

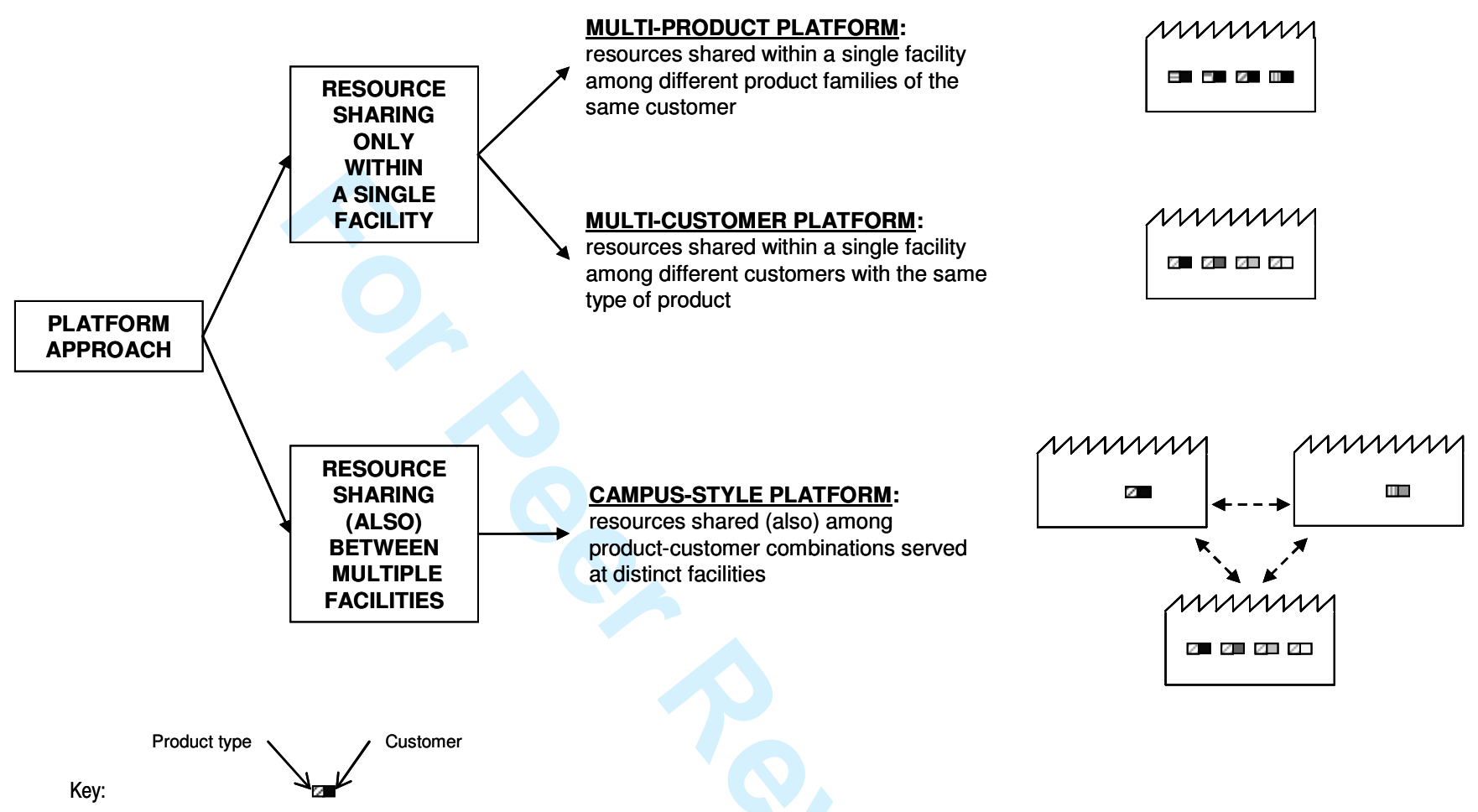

Figure 5. Organisational approaches adopted in the selected cases to provide FP services. 
Figure 6. The proposed framework linking FP service type, customer value, organisational approach and resource-sharing enablers.

\section{RESOURCE-SHARING ENABLERS}

- Similarity of workforce training requirements

- Similarity of equipment requirements

- Similarity of IT systems

- Dissimilarity of target markets

- Provision of a service including distribution

- Coordination by mutual adjustment

Observation 3

ORGANISATIONAL APPROACH

- Ad-hoc approach

- Platform approach

3PL FORM POSTPONEMENT SERVICE
- Existing PDA
-From-forecast-to-order-driven-PDA
-Remaining-forecast-driven-PDA
-Remaining-order-driven-PDA
- PDA-enabling

Observation 2

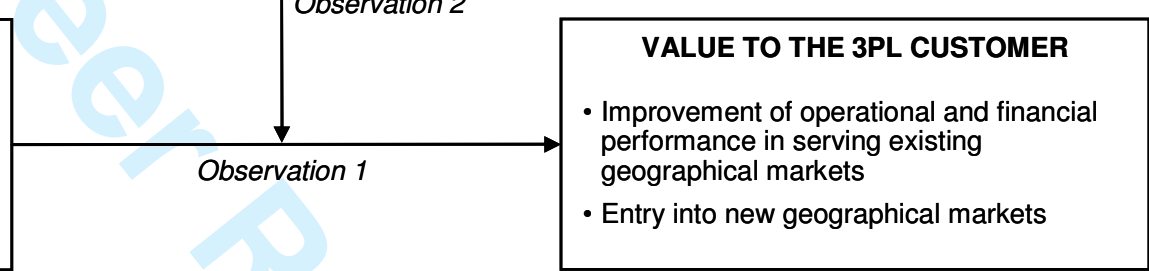

